\title{
The effect of image search, social influence characteristics and anthropomorphism on purchase intention in mobile shopping*
}

\author{
Won-Gu KIM ${ }^{1}$, Hyeonsuk PARK ${ }^{2}$
}

Received: April 21, 2020. Revised: May 30, 2020. Accepted: June 05, 2020

\begin{abstract}
Purpose: The purpose of this study is to review the previous studies on the characteristics of the image search service provided by using artificial intelligence, the social impact characteristics, and the moderating effect of perceived anthropomorphism, and conduct empirical analysis to identify the constituent factors affecting purchase intention. To clarify. Through this, I tried to present theoretical and practical implications. Research design, data, and methodology: Research design was that characteristics of image search service (ubiquity and information quality) and social impact characteristics (subjective norms, electronic word of mouth marketing) are affected by mediation of satisfaction and flow, therefore, control of perceived anthropomorphism have an effect on purchase intention to increase. For analysis, research conducted literature review, and developed questionnaires, so that EM firm which is a specialized research institute has collected data. This was conducted on 410 people between the $20 \mathrm{~s}$ and $50 \mathrm{~s}$ who have mobile shopping experiences. SPSS Statistics 23 and AMOS 23 had been used to perform necessary analysis such as exploratory factor analysis, reliability analysis, feasibility analysis, and structural equation modeling based on this data. Results: first, ubiquity, information quality and subjective norms were found to have a positive effect on purchase intention through satisfaction and flow parameters. Second, satisfaction and flow were found to have a mediating effect between ubiquity, information quality, and subjective norms and purchase intentions. However, there was no mediating effect between eWOM information and purchase intention. Third, perceived anthropomorphism was found to have a moderating effect between information quality and satisfaction, and it was found that there was no moderating effect on the relationship between information quality and flow. Conclusions: The information quality of image search services using artificial intelligence has a positive effect on satisfaction, and it has been found that there is a positive moderate effect of perceived anthropomorphism in this relationship, which may be an academic contribution to the distribution science utilizing artificial intelligence. Therefore, it is possible to propose a distribution strategy that improves purchase intention by utilizing image search service and anthropomorphism in practical business and providing a more enjoyable immersive experience to customers.
\end{abstract}

Keywords : Image Search, Social Influence, Artificial Intelligence, Anthropomorphism, Mobile Shopping

JEL Classification Code: M15, M30, M31

\footnotetext{
* Acknowledgements (if any): If there is any acknowledgement that authors would like to mention, please mention here.

1 First Author, ABD, Dept. of Convergence Industry, Seoul Venture University, Korea. Email: kwg1004@gmail.com

2 Corresponding Author, Professor, Dept. of Convergence Industry, Seoul Venture University, Korea. Tel: +82-2-3470-5244,

Email: hspark@svu.ac.kr

(c) Copyright: The Author(s)

This is an Open Access article distributed under the terms of the Creative Commons Attribution Non-Commercial License (https://creativecommons.org/licenses/by-nc/4.0/) which permits unrestricted non-commercial use, distribution, and reproduction in any medium, provided the original work is properly cited.
}

\section{1. 서론}

온라인 거래가 매년 증가하고 있어 2019 년 한 해 동안 국내 온라인 거래금액은 134 조원에 달했다. 이중 모바일 쇼핑거래금액은 86 조원으로 전체 온라인 거래 금액의 $64 \%$ 에 해당하는 규모이다. 그리고 국내는 스마트폰을 국민 1 인당 평균 1 대씩 보유하고 있으며 1 일 24 시간 항상 휴대하고 있고, 통신 기술의 발달로 언제 어디서나 거의 불편함 없이 스마트폰으로 모바일 인터넷에 접속이 가능하다. 따라서 모바일 쇼핑 시장의 관점에서 보면 24 시간 가동될 수 있는 
모바일 유통채널이 형성되어 있다고 볼 수 있다. 그러므로 모바일 쇼핑몰에서 이용자가 원하는 상품을 쉽게 검색하여 찾을 수 있도록 하는 것은 매우 중요하다.

이에 대하여 먼저 모바일 쇼핑(Mobile Shopping)에 관한 개념을 보면 모바일 쇼핑은 무선 전자상거래 (Frolidk \& Chen, 2004), 또는 휴대폰으로 정보 검색 및 구매하는 모든 형태의 거래 등으로 정의되고 있고(Au \& Kauffman, 2008; Wolf, Bid, \& Kummer, 2017), 또한 시간, 공간, 환경의 제약으로부터 자유롭다(Zhou \& Lu, 2011)는 특성이 있으며, 모바일 쇼핑 시장의 거래 유형에는 $\mathrm{B} 2 \mathrm{~B}, \mathrm{~B} 2 \mathrm{C}, \mathrm{OC}$, 금융거래 서비스 등 모바일 환경에서 이루어지는 모바일 전자 상거래의 다양한 형태가 있다(Huang, Lu, \& Ba, 2016; Wolf et al, 2017). 이러한 모바일 쇼핑몰에 관해 중요한 선행연구를 살펴보면 DeLone and Mdean (2003)등에 의해 정보품질, 시스 템품질, 서비스품질, 인터페이스품질 등 품질에 관한 많은 연구 들이 진행되었다Pitt, Watson, \& Kavan, 1995; Petter \& Mclean, 2009). 그리고 인지된 가치에 관한 연구 (McDougall \& Levesque, 2000; Dwivedi, Shareef, Simintiras, Lal, \& Weerakkody, 2016), 구매의도 감소에 영향을 주는 지각된 위험에 관한 연구(Maniné, Forsythe, Kwon, \& Chattaraman, 2012; Chang \& Tseng, 2013), 모바일 구전(eWOM)의 커뮤니케이션 및 신뢰 등에 관한 연구Wang, Shen, \& Sun, 2013; Jun \& Lee, 2015; Jun \& Lee, 2016; lin, Hsu, Chen, \& Fang, 2017; Km, Kim, Hur, Seo, \& Seo, 2020), 충동구매에 관한 연구(Wells, Parboteeah, \& Valacich, 2011; Xiang, Zheng, Lee, \& Zhao, 2016), 모바일 쿠폰을 활용하는 모바일 마케팅에 관한 연구(Mohammad \& Razli, 2011)등 다양한 연구사례가 있다.

그러나 최근 인공지능의 발달로 인해 모바일 쇼핑몰에서 제공되기 시작한 챗봇서비스 및 이미지 검색 분야에 대해서는 필요한 연구가 거의 없는 실정이다. 따라서 모바일 쇼핑몰의 검색분야 관하여 필요한 연구를 진행하고자 한다. 현재 모바일 쇼핑 몰에서 제공되는 검색 서비스의 유형은 텍스트 검색, 음성 검색, 이미지 검색으로 크게 구분된다. 최근 Big Data 와 4 차 산업혁명의 첨단 기술인 인공지능(AI : Artificial Intelligence)의 결합으로 모바일 쇼핑에 음성검색을 이용할 수 있는 챗봇(채팅'과 '로봇'을 합성한 용어)서비스, 이미지 검색서비스가 제공되기 시작하여 검색에 새로운 변화가 일기 시작 했다. 이에 따라 챗봇 서비스, 모바일 쇼핑몰에서 이용되는 이미지 검색서비스, 이미지 검색광고 등에 관한 연구가 있으나 아직은 부족한 실정이다. 따라서, 본 연구에서는 인공지능을 활용하는 이미지 검색 서비스의 중요한 특성과 사회적 영향 특성이 모바일 쇼핑몰에서 구매의도와 어떤 영향관계인지, 그리고 검색 서비스에 관한 의인화에 대해 지각하는 정도가 어떤 영향을 미치는지 등 관련 구성 요인들을 규명하여 인공지능을 활용하는 이미지 검색 서비스 전략에 대한 이론적, 실무적 시사점을 제시하고자 한다.

\section{2. 이론적 배경}

\section{1. 모바일 이미지 검색 특성}

이미지 검색서비스와 관련한 특성으로 편재성, 유희성, 정보품질, 시스템품질과 구매의도와의 관계를 연구한 결과 유희성과 정보품질은 구매의도에 유의한 영향이 있음이 확인되었다(Lim, Jo, Kho, \& Han, 2019). 또한 모바일 쇼핑 (커머스)의 특성으로 편재성, 접근성, 편리성, 개인화, 즉시 접속성(연결성) 등이 제시되었다(Siau, $\operatorname{Lim}, \&$ Shen, 2001). 따라서 이를 바탕으로 이미지 검색 서비스에 대한 하부 속성으로 편재성과 정보 품질을 중요한 요인으로 보고 이에 대하여 분석하고자 한다.

\subsection{1 편재성}

편재성(Ubiquity)은 사용자가 언제 어디서나 모바일 장치를 사용하여 비즈니스 활동이나 거래를 수행할 수 있는 능력으로서 유연성과 편리성을 제공해주는 것으로 정의된다(Sarkara, Chauhanb, \& Khare, 2020; Nikou \& Economides, 2017; Yoo \& Kim, 2019). 그리고 편재성의 특징은 모바일 이용자가 인터넷에 항상 접속하여 언제, 어디서나 여러가지 정보를 활용할 수 있어 (Kannan, Chang, \& Whinston, 2001), 모바일 단말기를 통해 시간, 장소의 제약 없이 제품, 서비스, 정보를 거래할 수 있는 것이며, 이것은 모바일 상거래의 가장 고유한 특징이다(Keijnen, Ruyter, \& Wetzels, 2007). 또한 편재성은 서비스 이용의 시간 및 공간적 제약조건의 제거로 이용자의 지각된 가치를 증가시킨다(Tojib \& Tsarenko, 2012). 따라서 편재성은 모바일 쇼핑의 주된 속성 (Garke, 2008) 이라고 할 수 있다.

\subsection{2. 정보품질}

정보품질은 정보시스템(S: Information System)에서 제공되는 정보에 대한 정확성, 적시성 및 완전성의 충 족에 관한 것으로 출력의 특성으로 정의되며, 정보품 질과 사용의도의 사이에, 또한 정보품질과 만족도의 사이에 유의하고 긍정적인 관계가 있는 것으로 확인되 었다Petter \& Mdean, 2009; Negash, Ryan, \& Igbania, 2003). 그리고 IS 성공모델, 수정 IS 성공모델과 이 모델들을 활용한 다양한 연구에서도 정보품질, 시스템품질, 서비스 품질이 유용성, 용이성, 만족, 행동의도 등에 중요한 영향이 미치는 것이 확인되었다DeLone \& Mclean, 2016; Wixom \& Todd, 2005). 이러한 정보품질은 정확성, 최신성, 적시성, 신뢰성, 완전성 등으로 측정하며(Seddon, 1997), 연구자에 따라 속성의 중요성에 관한 주장은 조금씩 다르다. Ahn, Ryu, and Han (2004) 등 연구자는 정보품질의 적시성, 최신성, 정확성 등이 중요한 것으로 주장하였다. 그러나 정보의 최신성, 적시성을 균일하게 유지하는 정보품질 관리가 중요한 것으로 
주장하기도 한다(DeLone \& Mdean, 2003). 또한 Shama and Shama (2019)는 정보품질이 사용에 대한 만족도와 사용자의 사용의도에, 그리고 만족은 사용의도에 영향이 미치는 것을 확인하였고, IS 관련 선행연구들과 일치(Chattejee, Kar, \& Gupta, 2018)한다고 하였다.

\section{2. 사회적 영향 특성}

Venkatesh, Monis, and Davis (2003)는 사회적 영향에 대한 정의를 개인이 다른 중요한 사람들이 새로운 시스템을 사용해야 한다고 믿는다는 것을 인식하는 정도로 정의했다. 이러한 사회적 영향 에 관계되는 이론들인 합리적 행동이론(TRA), 계획행동이론 (TPB) 및 기술수용모델(TAM : Technology Acceptance Model)에서 사회적 변인으로 주관적 규범, 사회적 이미지, 적합성 등에 대하여 규명되었다. 또한 인터넷이 사회적 영향 범위를 확장했기 때문에 집단 규범, 주관적 규범 등 사회적 규범(social nom)은 중요하고 가까운 구성원 이외의 영향도 고려해야 하며, 구전정보를 사회적 영향의 원천으로 보았다Osatuyi \& Turel, 2019). 따라서 본 연구에서는 이미지 검색 서비스 수용에 사회적 영향이 크다고 판단되는 주관적 규범과 정보전달의 매개역할을 하는 구전정보를 사회적 영향 특성의 하부 요인으로 분석하고자 한다.

\subsection{1 주관적 규범}

주관적 규범은 자신이 속해있는 준거집단이 자신에게 어떻게

행동할 것인지를 기대한다고 인지하는 것 또는 사회적 압력이다 Nenkatesh \& Davis, 1996). 그리고 주관적 규범은 Shaw and Sergueeva (2019)에 의하면 개인은 친구, 가족의 설득으로 모바일 상거래에 참여할 수 있고 타인에게 깊은 인상을 줄 것이라고 했다. 이러한 주관적 규범은 사회적 영향 변수의 대표적 변인으로 이미지, 가시성, 자발성 등과 함께 연구되어 왔고, 지각된 유용성, 사용의도에 강한 영향을 미친다Carolina, Francisco, \& Hary, 2008)는 연구결과가 있다. 또한 주관적 규범은 모바일 쇼핑에서 만족도를 결정하는 중요한 요인이 되는 것이다(Sonia, Jana, \& Blanca, 2016).

\subsection{2. 구전정보}

구전(eWOM; electronic Word of Mouth)은 자신이 이용하여 얻은 정보들을 인터넷 매체를 통해 타인에게 전달하는 것이다 Wang et al, 2013; Inobe \& Elizabeth, 2019). 또한 모바일 eWOM 커뮤니 케이션은 모바일 인터넷을 통해 제품, 서비스, 회사에 대한 잠재적, 실제 또는 이전 고객과의 사이에 긍정적, 부정적인 커뮤니케이션으로 볼 수 있다(HsiaO, Chang, \& Tang, 2016; Ekkan \& Evans, 2016). 그리고 SNS 구전정보에 대해 최신성, 시간절약성, 편의성, 정확도 등으로 측정하여 실제 행동의도에
긍정적인 영향이 미치는 것으로 확인되었다(Zhu, Wymer, \& Chen, 2002; Yadav, Sharma, \& Tarhini, 2015).

\section{3. 만족, 플로우, 의인화 및 구매의도}

\subsection{1. 만족}

만족은 모바일 환경에서 관계를 유지한 결과를 바탕으로 긍 정적, 정서적 상태뿐만 아니라 기대를 충족시키는 것을 의미한 다(Estela \& Sergio, 2016. 고객은 자신이 지각하고 있는 품질 및 그에 따른 성과로 만족을 느끼게 된다. 만족은 사용자 만족이 향상될수록 지속사용의도가 커지고(Lmayem \& Cheung, 2008), 정보품질이나 기대치와 실제적 지각수준 등이 소비자 만족에 영향을 미치며(Chen, 2013), 신뢰도, 관여도 및 혁신성도 모바일 쇼핑 만족에 영향이 미치는 것으로 확인되었다(Sonia et al, 2016). 이러한 만족은 제품이나 상표에 대한 경험 후의 태도와 비슷한 측면이 있고 태도와는 구분되고(Park \& Park, 2013), 의사소통에서 정보에 대한 사용자의 태도나 성과지표로 사용되는 등 많은 연구들이 있다(Cha \& Seo, 2019; Lee \& Kim, 2019; Cha \& Lee, 2020; Cho, 2020).

\subsection{2. 플로우(Flow)}

플로우(How)는 사람들이 완전히 몰입하여 행동할 때 느끼는 총체적 경험, 즉 통제, 주의, 호기심 및 본질적인 관심의 4 가지 구성 요소로 구성되어 있다고 정의한다(Csikszentmihalyi, 1997). 그리고 플로우 경험의 핵심적인 특징은 즐거움과 주의집중 이며(Ghani \& Deshpande, 1994), 인터넷과 상호작용 및 피드백의 경험을 하면서 인터넷 활동에 흥미를 느끼며 즐겁기 때문에 외부의 보상이 없어도 인터넷에 지속적으로 집중하게 되는 특징이 있다(Hoffman \& Novak, 1996). 또한 정보기술을 자발적으로 사용하게 되는 것도 플로우 경험과 관계가 있는 것이다 (Webster, Trevino, \& Ryan, 1993). 이러한 플로우는 향후 만족도, 충성도 등 결과에 정(+)의 영향을 미친다는 것으로 밝혀졌다 (Trevino \& Webster, 1992). 그리고 플로우 개념을 이용한 분석에서 웹사이트에서 느낀 즐거움의 경험은 인터넷 구매의도를 증대 시킬 수 있다고 했다. 모바일 쇼핑경험은 유용성, 만족도, 구매 의도 등에 영향을 미치는 연구결과들이 있다(Hoffman \& Novak, 1996; Sarkar \& Khare, 2019).

\subsection{3. 인지된 의인화}

의인화(Anthropomorphism)는 인간이 아닌 무생물, 동물 등 의인화 대상에 인간의 속성을 부여하여 인간처럼 표현하려는 것이다티ley, Wayt, Akalis, \& Cacioppo, 2008). 의인화 유형에는 브랜드 의인화, 챗봇 의인화, 제품의 의인화 등이 있다(Chandler \& Schwarz, 2010). 모바일 쇼핑몰 등에서 사용되는 가상캐릭터 (virtual character)는 사람의 모습을 
닮도록 의인화된 미디어 화면 속의 캐릭터이다(Craig \& Schroeder, 2017). 가상캐릭터에 대한 의인화 지각은 멀티미디어 학습환경에서 가상캐릭터와 상호 작용하는 것이 마치 사람과 하는 것과 같은 지각을 하게 되는 심리적인 평가(Moreno, Mayer, Spires, \& Lester, 2001)로서 의인화 효과를 만들어 학습자의 흥미 및 학습동기를 향상시킬 수 있는 것이다(Koo, Shoffner, \& Ryu, 2017). 최근 등장한 챗봇 (dhatbot)은 메시지 플랫폼 내에서 구동되는 서비스로서 텍스트화를 이용 하여 여러가지 정보나 솔루션을 제공하는 인공지능 기반의 프로그램을 의미한다(Astrid, Kramer, Gratch, \& Kang, 2010). 챗봇의 의인화에 관한 연구에서 인간과 유사한 언어, 이름을 사용하여 의인화된 챗봇이 더 긍정적이라고 인식했고, 자동차에 사람 이름, 성별, 목소리 등과 같은 인간적인 속성으로 의인화를 한 경우가 신뢰성과 안전성이 더 높게 나타났다(Wayt, Morewedge, Epley, Monteleone, Gao, \& Cacioppo, 2010; Chandler \& Schwarz, 2010). 즉 모바일 쇼핑몰에서 의인화된 이미지가 더 영향을 미치며, 이용자는 의인화된 디자인을 가지고 있는 제품을 더 긍정적으로 평가한다는 것이다(Aggarwal \& McGill, 2007).

\subsection{4. 구매의도}

구매의도는 특정 상품을 구매하려는 개인적 입장에서 계획 되거나 의도된 행동이 신념 및 태도로 바뀌어져 행동으로 옮겨 질 가능성을 의미하는 것이다(Engel, Bladkwell, Roger, \& Miniard 1995). 그리고 구매의도는 소비자의 태도와 신념이 실제 구매행위로 구체화될 확률이며 구매의도는 제품을 실제로 구매하게 되는 것과 상관관계가 높다고 했다(Engel et al, 1995). 또한 구매의도는 개인의 태도 및 신념이 구체적 행위로 나타날 확률을 의미하는 것이라는 비슷한 주장이 있으며, 모바일 환경에서 소비자 만족을 매개로 구매의도에 영향을 미친다는 많은 연구결과들이 있고, 만족한 고객은 서비스를 계속 사용하려는 강한 의도를 가지고 있어 만족은 계속 사용의도나 재구매의도에도 강한 영향을 미친다고 하였다(Swan, 1985; McDougall \& Levesque, 2000; Baker \& Cromp ton, 2000; limayem \& Cheung, 2008; Estela \& Sergio, 2016)

\section{3. 연구모형 및 가설}

\section{1. 연구모형}

본 연구에서 연구모형은 행동규범적 신념의 태도 및 주관적 규범과, 행위의도, 행위 사이의 관계를 규명 한 합리적 행동이론모델(Fishbein, 1967), 또한 여기에 지각된 행동통제를 추가한 계획적 행동이론 모델(Aizen, 1991)등 선행연구 모델을 활용하여 Figure 1 과 같이 일부 변인을 추가 등 확장설계하였다. 그리고 앞서 살펴본 선행 연구를
바탕으로 모바일 쇼핑에서 인공지능을 활용하는 이미지 검색기능과 의인화 및 사회적 영향이 구매의도에 미치는 영향을 파악하기 위하여 이미지 검색 특성(편재성, 정보품질) 및 사회적 영향 특성(주관적 규범, 구전 정보과 만족, 플로우, 지각된 의인화가 구매의도에 미치는 영향관계를 Figure 1 과 같이 제시하였다.

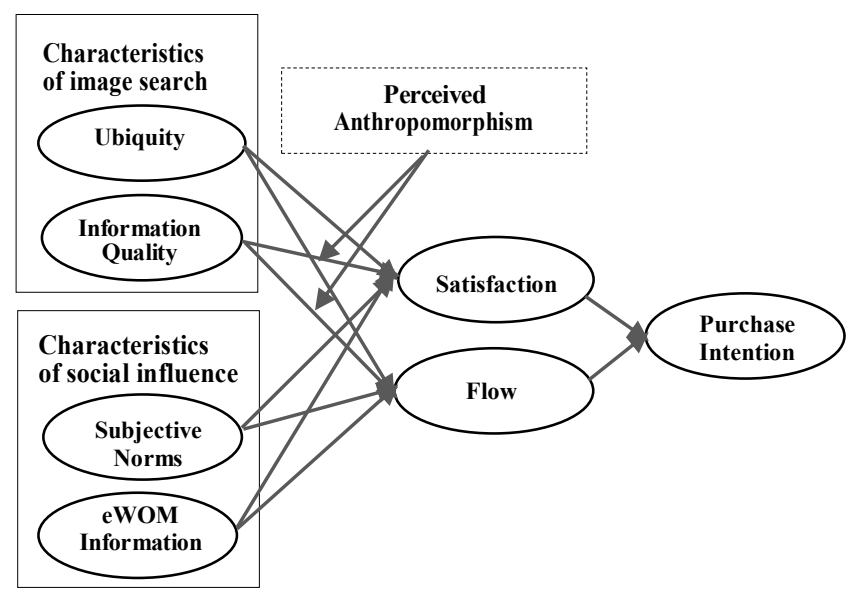

Figure 1 : Research Model

\section{2. 연구가설}

선행연구들을 살펴보면 Okazaki and Mendez (2013)가 Novak and Hoffman (1996)이 제시한 원격실재감 (telepresence)을 지각된 편재성(perceived ubiquity)으 로 대체한 연구에서 편재성이 플로우에 영향이 미치는 것을 확인하였다. 또한 편재성은 시공간 제약 없이 유연 성과 편리성을 제공해주므로 사용의도에도 영향을 미치는 요인으로 검증되었다 (Sarkara et al, 2020; Yoo \& Km, 2019). 그리고 Hausman and Siekpe (2009), Wang and Huang (2014), Bao and Huang (2018) 등은 플로우가 정보품질에 의해 직간접적으로 긍정적 영향을 받는다고 하였다. 또한 정보 품질은 정보의 속성, 품질에 관한 것으로서 구매의도에 유의한 영향을 주고(lim et al, 2019; Ahn et al, 2004), 정확성의 정보품질은 만족에 영향을 미치는 것으로 확인되었다Cho, Potun, \& Youn, 2020; Cho, 2019). 따라서 아래와 같이 가설을 설정하였다.

H1-1 : 편재성은 만족에 정(+)의 영향을 미칠 것이다.

H1-2: 편재성은 플로우에 정(+)의 영향을 미칠 것이다

H2-1: 정보품질은 만족에 정 $(+)$ 의 영향을 미칠 것이다.

H2-2: 정보품질은 플로우에 정(+)의 영향을 미칠 것이다.

주관적 규범은 Venkatesh and Davis(2000)와 Pedersen (2005)등에 의해 행동의도에 정의(+) 영향을 미치고 있음이 확인되었다. 또한 주관적 
규범은 구매의도와 관련이 있고, 의사 결정에 영향을 미치는 의견이며, 개인의 태도와 주관적 규범 및 인지된 행동은 구매의도와 유의한 상관관계가 있다고 했다(Chen, 2013; Sonia et al, 2016). 그리고 Inobe and Elizabeth (2019)은 구전정보 (eWOM)의 사용, 주관적 규범, 인식된 행동 통제, 태도의 조합은 재방문의도에 큰 영향을 미친다고 했다. 또한 구전은 행동의도에 영향을 미치고 (Yadav et al., 2015), SNS 정보특성에 관한 연구에서도 행동의도에 긍정적인 영향이 미치는 것으로 확인되었다Cha \& Lyu, 2019). eWOM 에는 사실정보, 소비, 브랜드 관련 경험이 포함 되어 있어 신뢰에 영향을 주며 신뢰는 구매의도에 영향을 미친다 (Erkan \& Evans, 2016)고했다. 구전정보는 신뢰와 주관적 규범에 영향을 미치며(Fu, Bin, Xie, Lulli, \& Yu, 2011; Jallivand \& Samiei, 2012), 신뢰와 주관적 규범은 유용성에 영향을 미치고 (Horst, Kuntschreuter, \& Gutteling, 2007), 신뢰는 플로우 에 영향을 준다(Wu \& Chang, 2005)고 했다. 또한 사회적 규범, 주관적규범은 유용성에 영향을 미치고 (Fetscherin \& Lattemann, 2008; Ángela \& Ángel, 2017), 쾌락과 유용성은 플우에 영향을 미친다고 했다 (Bilgihan, Nusair, Okumus, \& Cobanoglu, 2015; Jamshidi, Keshavarz, Kazemi, \& Mohammadian, 2018). 따라서 아래 와 같이 주관적 규범과 구전정보에 관한 가설을 설정하였다.

H3-1 : 주관적 규범은 만족에 정(+)의 영향을 미칠 것이다.

H3-2 : 주관적 규범은 플로우에 정(+)의 영향을 미칠 것이다.

$\mathrm{H41}$ : 구전정보는 만족에 정(+)의 영향을 미칠 것이다.

H42: 구전정보는 플로우에 정(+)의 영향을 미칠 것이다.

만족은 충성도에 영향을 미치고, 만족도와 수용의도와는 관련성이 있고, 만족을 충족시켜야 구매의도와 연결된다 하였다(Limayem \& Cheung, 2008). 또한 고객 만족은 재구매의도 및 행동의도와 같은 후속 행동 의도로 이어질 수 있고, 고객만족 도는 재구매의도를 향상시켜 주며 (McDougall \& Levesque, 2000), 고객 만족이 구매 후 태도에도 영향을 미치고 재구매의도에 영향을 미친다고 했다. 그리고 플로우 경험은 지각된 유용성과 태도에 영향을 미쳐 이용 지속의도에 영향을 미치고, 향후 만족도, 충성도 등 결과에 정의 영향을 주고(Trevino \& Webster, 1992), 만족스러 운 경험은 재구매 의도를 높인다 (Agrebi \& Jallais, 2015; Estela \& Sergio, 2016)고 했다. 또한 플로우(How) 개념에 관한 연구에서 즐거움의 경험이 인터넷 구매의도를 증대시킬 수 있음이 확인되었다(Hoffman \& Novak, 1996). 또한 플로우는 온라인과 모바일 환경에서 태도에 긍정적인 영향이 미치는 (Zhou \& Lu, 2011)는 것으로 검증되었다. 그러므로 만족과 플로우를 매개변인으로 선정하여 아래와 같이 가설을 설정하였다.

H5: 만족은 구매의도에 정(+)의 영향을 미칠 것이다.

H6: 플로우는 구매의도에 정(+)의 영향을 미칠 것이다.
H7-1 : 편재성은 만족과 플로우를 경유하여 구매의도에 정(+)의 영향을 미칠 것이다.

H7-2 : 정보품질은 만족과 플로우를 경유하여 구매의도에 정(+)의 영향을 미칠 것이다.

H7-3 : 주관적 규범은 만족과 플로우를 경유하여 구매의도에 정(+)의 영향을 미칠 것이다.

H7-4 : 구전정보는 만족과 플로우를 경유하여 구매의도에 정(+)의 영향을 미칠 것이다.

선행연구에서 소비자는 의인화된 디자인 제품을 더 선호한 다Aggarwal \& McGill, 2007)고 하였다. 즉 이름, 목소리 등을 의인화한 기능을 가진 자동차를 더 신뢰하므로 의인화된 자동차는 사용자의 신뢰성을 높여(Wayz et al, 2010) 소비자의 선호도를 높인다Wan, Chen \& $\mathrm{Jin}$, 2017). 또한 의인화 효과를 만들어 학습자의 흥미 및 학습동기를 향상시킬 수 있고(Koo et al, 2017), 챗봇을 사람처럼 느끼게 하고 재미있게 하면 고객들은 만족해 한다(Kwak, Km, \& Km, 2019)고 한다. 따라서 이를 바탕으로 아래와 같이 가설을 설정하였다.

H8-1 : 지각된 의인화는 정보품질과 만족 간에 조절역할을 할 것이다. H8-2: 지각된 의인화는 정보품질과 플로우 간에 조절역할을 할 것이다.

\section{4. 조작적 정의 및 실증 분석}

\section{1. 자료의 수집 및 분석 방법}

본 연구에서는 분석에 필요한 데이터 수집을 위한 설문을 작성하여 리서치 전문기관인 EM 사를 통해 2020 년 2 월에 온라인 방식으로 설문을 실시하였고 회수된 513 부 중 유효한 410 부를 분석에 사용하였다. 분석단위는 모바일 쇼핑몰을 이용하는 20 대에서 50 대까지 이며 층화추출 방식으로 표본을 추출하였고 7 점 리커트 척도를 사용하였다. SPSS 23 을 활용해 빈도분석, 탐색적 요인 분석, 신뢰도 분석 등을 실시하였고, AMOS 23 을 활용하여 타당성, 적합도, 매개효과분석 등 필요한 분석을 실시하였다.

\section{2. 변수의 조작적 정의 및 측정}

선행연구를 바탕으로 변수에 대한 조작적 정의를 하고 변수별 설정된 측정변수를 측정하였다. 편재성은 누구든지 언제, 어디서나 필요한 정보를 즉시 얻을 수 있는 정도로 정의한다 (Siau et al, 2001; Sarkara et al, 2020). 정보 품질은 충분성, 정확성, 최신성, 적절성 등을 잘 반영하여 
설명하는 정도로 정의한다 (Shama \& Shama, 2019; Lim et al, 2019). 주관적 규범은 특정한 행위를 해야 한다거나 하지 말아야 한다는 사회적인 압력 정도로 정의한다Nenkatesh \& Davis, 2000; Shaw \& Sergueeva, 2019). 구전정보에 대하여 Hsiao et al.(2016) 등은 스마트폰 등 모바일 단말기를 통해 모바일 쇼핑몰에서 검색할 때 검색 대상에 대한 사용 경험에 관하여 설명한 정보 정도로 정의한다(Erkan \& Evans, 2016; Wang et al, 2013). 만족은 모바일 쇼핑에서 소비자의 기대나 욕구가 충족되어 소비자가 전반적으로 느끼는 기쁨 또는 흡족해하는 정도로 정의한다Estela \& Sergio, 2016; Chen, 2013). 플로우(How)는 모바일 쇼핑을 이용 하는 것이 쉽고, 편리하고 매력과 즐거움을 느끼며 몰입하게 되는 상태로 정의한다(Novak, Hoffman, \& Yung, 2000; Hoffman \& Novak, 1996). 지각된 의인화는 인간이 아닌 무생물에 인간적 속성을 부하여 인간처럼 표현하려는 정도로 정의한다Epley, Wayt, Akalis, \& Cacioppo, 2007; Aggarwal \& McGill, 2007). 구매 의도는 모바일 쇼핑몰 에서 이미지 검색, 상황적 영향 등에 의해 제품 및 서비스를 구매하려는 의지 정도로 정의한다(Estela \& Sergio, 2016; Limayem \& Cheung, 2008).

\section{3. 빈도 및 인구통계학적 분석}

인구통계학적 특성은 Table 1 과 같다. 표본 대상 응답자들의 일반 사항은 남녀 비율이 남자 $35.4 \%$, 여자 $64.6 \%$ 였고, 연령대는 20 대 $24.1 \%$, 30 대 $322 \%, 40$ 대 $32.4 \%, 50$ 대 $112 \%$ 로 30 대와 40 대의 설문응답자가 많았다. 분석에 사용된 410 명은 모두 모바일 쇼핑몰 이용자로서 매월 $3 \sim 4$ 회이상 이미지 검색을 이용하는 비율은 $41.2 \%$ 로 나타났다. 학력은 대졸이 이상이 330 명으로 응답자 전체의 $80.5 \%$ 이었다. 직업 분포는 사무 및 관리직 $49.8 \%$, 전문 및 연구직 $11.5 \%$, 자영업자 $4.1 \%$ 등 이었다.

\section{4. 탐색적 요인 및 신뢰도 분석}

SPSS 23 을 활용하여 먼저 탐색적 요인분석으로 타당성 검증을 실시하였다. 직교회전방식을 채택하여 적재량을 단순화하였고 측정변수는 주성분 분석을 이용하였다. 요인과 문항의 선택 기준에 관한 고유값을 1.0 , 요인 적재량을 0.7 이상, 표본의 적절성을 위한 $\mathrm{KMO}$ 를 0.5 이상으로 하였다. 탐색적 요인분석 결과는 Table 2 와 같으며 요인적재량은 0.607 에서 0.867 로 대부분 기준치 이상이고, 구매의도의 측정변수 4 개가 .607 에 서 688 이지만 사용할 수 있다는 의견도 있고(송지준 2019), 고유값은 3.349 에서 6.028 로 모두 기준치 이상으로 나타났기 때문에 측정항목 제거 없이 48 개 요인이 추출되었다. 그리고 개별요인 들간의 표본 적절성의 KMO(Kaiser-Meyer-Olkin) 측도는 965 로 높게 나타났고, $\mathrm{p}=000$ 으로 유의하여 변수 선정은 타당성이 확인 되었다. 그리고 내적 일관성을 확인하기 위하여 신뢰도분석을 실시하고 Cronbach's $\alpha$ 값은 0.6 이상을 기준으로 판단하였다 (Song, 2019). 신뢰도
분석결과는 Table 2 과 같으며 각 변수들의 Cronbach's $\alpha$ 값은 0.892 0.968 로 나타나 높은 신뢰도를 나타냈다.

Table 1 : Frequency Analysis on the general characteristics

\begin{tabular}{|c|c|c|c|}
\hline Variable & Items & Frequency & (\%) \\
\hline \multirow{3}{*}{ Gender } & Male & 145 & 35.4 \\
\cline { 2 - 4 } & Female & 265 & 64.6 \\
\hline \multirow{4}{*}{ Age } & 20 's & 99 & 24.1 \\
\cline { 2 - 4 } & 30 's & 132 & 32.2 \\
\cline { 2 - 4 } & 40 's & 133 & 32.4 \\
\cline { 2 - 4 } & 50's & 46 & 11.2 \\
\hline \multirow{3}{*}{$\begin{array}{c}\text { Edu- } \\
\text { cation }\end{array}$} & High school & 42 & 10.2 \\
\cline { 2 - 4 } & university student & 38 & 9.3 \\
\cline { 2 - 4 } & University graduate & 330 & 80.5 \\
\hline \multirow{3}{*}{$\begin{array}{c}\text { Number } \\
\text { Search Image }\end{array}$} & Less than 3 times & 241 & 58.8 \\
\cline { 2 - 4 } & 3-4 times per month & 58 & 14.1 \\
\cline { 2 - 4 } & more than 5 a month & 111 & 27.1 \\
\hline \multirow{4}{*}{ Job } & Professional, Research & 47 & 11.5 \\
\cline { 2 - 4 } & executive & 204 & 49.8 \\
\cline { 2 - 4 } & self-employment & 17 & 4.1 \\
\cline { 2 - 4 } & the others & 142 & 34.6 \\
\hline
\end{tabular}

\section{5. 확인적 요인 분석}

탐색적 요인 분석과 신뢰도 분석을 진행한 개별 잠재변수에 대해 AMOS 23 을 활용하여 확인적 요인 분석을 실시하였다. 적합도는 $\mathrm{CMIN} / \mathrm{DF}\left(\mathrm{x}^{2} / \mathrm{df}\right)<3, \mathrm{RMR} \leq 0.08$, GH $\geq 0.8$, AGH $\geq 0.8$, RMSEA < 0.05(0.05 0.1 : 수용), 그리고 NF, IF, TL, CF 는 0.9 이상을 기준으로 판단하였다(Song, 2019). 높은 적합도를 생성하기 위하여 SMC 0.4 이하를 하나씩 제거하는 과정을 반복하여 Table3 에서와 같이 최종 남아있는 변수(constructs) 전체를 대상으로 확인적 요인분석 최종 실시결과 $X$ ${ }^{2}=498206, \mathrm{DF}=411, \mathrm{P}=0.000$ 으로 나타났다. 그리고 절대적합지수는 $\mathrm{CMIN} / \mathrm{DF}=\mathrm{x}^{2} / \mathrm{df}=1212, \mathrm{GH}=0.919, \mathrm{AGH}=0.902, \mathrm{RMSEA}=0.024$ 이었다. 또한 증분 적합지수도 $\mathrm{NH}=0.927, \mathrm{IH}=0.986, \mathrm{CH}=0.986$ 로 나타나 적합 기준에 적합함을 확인하였다.

\section{6. 타당성 분석}

그리고 수렴타당성이라고도 하는 집중타당성은 잠재변수를 측정하는 관측변수들이 얼마나 일치하는 지를 알아보는 일치성의 정도에 관한 것이다. 검증방법은 개념신뢰도 값(CR)이 0.7 이상일 때, 평균분산 추출 
값 (AVE)값이 0.5 이상이면 측정변수들이 집중 타당성이 있다고 해석한다(Fomell \& Lacker, 1981).

Table 2 : Result of exploratory factor \& Reliability analysis

\begin{tabular}{|c|c|c|c|c|}
\hline Variables & Item & $\begin{array}{l}\text { Factor } \\
\text { loading }\end{array}$ & $\begin{array}{l}\text { Eigen } \\
\text { Value }\end{array}$ & Cronbach's $\alpha$ \\
\hline \multirow{6}{*}{$\begin{array}{l}\text { Perceived } \\
\text { Anthropo- } \\
\text { morphism }\end{array}$} & PA3 & .856 & \multirow{6}{*}{6.028} & \multirow{6}{*}{.968} \\
\hline & PA 2 & 843 & & \\
\hline & PA 1 & .822 & & \\
\hline & PA 5 & .821 & & \\
\hline & PA 6 & .759 & & \\
\hline & PA 4 & .735 & & \\
\hline \multirow{6}{*}{$\begin{array}{c}\text { Subjective } \\
\text { Norms }\end{array}$} & SN5 & .867 & \multirow{6}{*}{5.182} & \multirow{6}{*}{.945} \\
\hline & SN 6 & .849 & & \\
\hline & $\mathrm{SN} 4$ & .829 & & \\
\hline & SN 2 & .809 & & \\
\hline & SN 3 & .796 & & \\
\hline & SN 1 & .763 & & \\
\hline \multirow{6}{*}{ Flow } & FL4 & .801 & \multirow{6}{*}{5.118} & \multirow{6}{*}{.958} \\
\hline & FL 6 & .780 & & \\
\hline & FL 5 & .755 & & \\
\hline & FL 3 & .728 & & \\
\hline & FL 2 & .720 & & \\
\hline & FL 1 & .701 & & \\
\hline \multirow{6}{*}{ Ubiquity } & UQ5 & .814 & \multirow{6}{*}{5.101} & \multirow{6}{*}{.928} \\
\hline & UQ 6 & .806 & & \\
\hline & UQ 4 & .795 & & \\
\hline & UQ 3 & .778 & & \\
\hline & UQ 2 & .776 & & \\
\hline & UQ 1 & .771 & & \\
\hline \multirow{6}{*}{$\begin{array}{c}\text { Information } \\
\text { Quality }\end{array}$} & IQ2 & .787 & \multirow{6}{*}{5.056} & \multirow{6}{*}{.942} \\
\hline & IQ 5 & .784 & & \\
\hline & IQ 6 & .741 & & \\
\hline & IQ 4 & .734 & & \\
\hline & IQ 3 & .721 & & \\
\hline & IQ 1 & .705 & & \\
\hline \multirow{6}{*}{$\begin{array}{l}\text { Purchase } \\
\text { Intention }\end{array}$} & $\mathrm{PI} 6$ & .728 & \multirow{6}{*}{4.291} & \multirow{6}{*}{.952} \\
\hline & $\mathrm{PI} 2$ & .700 & & \\
\hline & $\mathrm{PI} 4$ & .688 & & \\
\hline & $\mathrm{PI} 1$ & .687 & & \\
\hline & $\mathrm{PI} 3$ & 686 & & \\
\hline & PI 5 & 607 & & \\
\hline \multirow{6}{*}{$\begin{array}{l}\text { eWOM } \\
\text { Information }\end{array}$} & WI6 & .826 & \multirow{6}{*}{4.29} & \multirow{6}{*}{.892} \\
\hline & WI 3 & .826 & & \\
\hline & WI 1 & .765 & & \\
\hline & WI 4 & .760 & & \\
\hline & WI 2 & .708 & & \\
\hline & WI 5 & .704 & & \\
\hline \multirow{6}{*}{ Satisfaction } & SF4 & .826 & & \\
\hline & SF 3 & .826 & & \\
\hline & SF 2 & .765 & 3349 & \\
\hline & SF 5 & .760 & 3.349 & .968 \\
\hline & SF 1 & .708 & & \\
\hline & SF 6 & .704 & & \\
\hline
\end{tabular}

Note: $\mathrm{KMO}=0.965, \mathrm{x}^{2}=21957.913, \mathrm{p}=.000$
Table 3 : Convergent Validity Evaluation

\begin{tabular}{|c|c|c|c|c|c|c|}
\hline \multicolumn{2}{|c|}{ research variable } & \multirow{2}{*}{$\begin{array}{c}\begin{array}{c}\text { Std. } \\
\text { Estimate }\end{array} \\
.880\end{array}$} & \multirow[t]{2}{*}{$\mathbf{p}$} & \multirow{4}{*}{$\begin{array}{l}\text { AVE } \\
0.665\end{array}$} & \multirow{4}{*}{$\begin{array}{l}\text { C.R. } \\
0.856\end{array}$} & \multirow{4}{*}{$\begin{array}{c}\begin{array}{c}\text { Cron- } \\
\text { bach's } \\
\mathbf{\alpha}\end{array} \\
0.928\end{array}$} \\
\hline \multirow{3}{*}{ Ubiquity } & UQ6 & & & & & \\
\hline & UQ5 & .881 & $* * *$ & & & \\
\hline & UQ4 & .864 & $* * *$ & & & \\
\hline \multirow{4}{*}{$\begin{array}{c}\text { Information } \\
\text { Quality }\end{array}$} & IQ6 & .843 & & \multirow{4}{*}{0.686} & \multirow{4}{*}{0.897} & \multirow{4}{*}{0.942} \\
\hline & IQ 5 & .891 & $* * *$ & & & \\
\hline & IQ 3 & .864 & $* * *$ & & & \\
\hline & IQ 2 & .881 & $* * *$ & & & \\
\hline \multirow{4}{*}{$\begin{array}{l}\text { Subjective } \\
\text { Norms }\end{array}$} & SN5 & .878 & & \multirow{4}{*}{0.594} & \multirow{4}{*}{0.854} & \multirow{4}{*}{0.945} \\
\hline & SN4 & .855 & $* * *$ & & & \\
\hline & SN2 & .872 & $* * *$ & & & \\
\hline & SN1 & .835 & $* * *$ & & & \\
\hline \multirow{4}{*}{$\begin{array}{c}\text { eWOM } \\
\text { Information }\end{array}$} & WI 6 & .904 & & \multirow{4}{*}{0.661} & \multirow{4}{*}{0.886} & \multirow{4}{*}{0.892} \\
\hline & W14 & .724 & $* * *$ & & & \\
\hline & WI3 & .814 & $* * *$ & & & \\
\hline & WI1 & .785 & $* * *$ & & & \\
\hline \multirow{4}{*}{ Satisfaction } & SF5 & .887 & & \multirow{4}{*}{0.774} & \multirow{4}{*}{0.932} & \multirow{4}{*}{0.968} \\
\hline & SF4 & .929 & $* * *$ & & & \\
\hline & SF3 & .931 & $* * *$ & & & \\
\hline & SF2 & .916 & $* * *$ & & & \\
\hline \multirow{4}{*}{ Flow } & FL 6 & .914 & & \multirow{4}{*}{0.781} & \multirow{4}{*}{0.935} & \multirow{4}{*}{0.958} \\
\hline & FL5 & .928 & $* * *$ & & & \\
\hline & FL4 & .904 & $* * *$ & & & \\
\hline & FL3 & .875 & $* * *$ & & & \\
\hline \multirow{3}{*}{$\begin{array}{l}\text { Perceived } \\
\text { Anthropo } \\
\text {-morphism }\end{array}$} & PA3 & .945 & & \multirow{3}{*}{0.786} & \multirow{3}{*}{0.917} & \multirow{3}{*}{0.968} \\
\hline & PA2 & .963 & $* * *$ & & & \\
\hline & PA1 & .914 & $* * *$ & & & \\
\hline & $\mathrm{PI} 6$ & .909 & & & & \\
\hline $\begin{array}{l}\text { Purchase } \\
\text { Intention }\end{array}$ & $\mathrm{PI} 4$ & .907 & $* * *$ & 0.732 & 0.891 & 0.952 \\
\hline & $\mathrm{PI} 3$ & .912 & $* * *$ & & & \\
\hline
\end{tabular}

Table 4 : Discriminant Validity Estimation

\begin{tabular}{|c|c|c|c|c|c|c|c|c|}
\hline CT & UQ & IQ & SN & WI & SF & FL & PA & PI \\
\hline UQ & 1 & & & & & & & \\
\hline IQ & 0.270 & 1 & & & & & & \\
\hline SN & 0.125 & 0.195 & 1 & & & & & \\
\hline WI & 0.166 & 0.125 & 0.130 & 1 & & & & \\
\hline SF & 0.293 & 0.554 & 0.258 & 0.112 & 1 & & & \\
\hline FL & 0.254 & 0.382 & 0.258 & 0.222 & 0.533 & 1 & & \\
\hline PA & 0.114 & 0.335 & 0.261 & 0.019 & 0.466 & 0.284 & 1 & \\
\hline PI & 0.252 & 0.516 & 0.240 & 0.080 & 0.632 & 0.446 & 0.456 & 1 \\
\hline AVE & 0.665 & 0.686 & 0.594 & 0.661 & 0.794 & 0.781 & 0.786 & 0.732 \\
\hline
\end{tabular}

Notes: CT : Construct, Ubiquity(UQ), Information Quality(IQ), Subjective Norms(SN), eWOM Information(WI), Satisfaction(SF), Flow(FL), Perceived Anthropomorphism(PA), Purchase, Intention(PI) 
집중타당 성을 분석한 결과 Table 3 에서 알 수 있듯이 CR 값 AVE 값은 모두 적합기준 이상이므로 집중타당성을 확보하였다고 할 수 있다. 판별타당성은 서로 독립된 잠재변수 사이의 차이를 나타내는 정도에 관한 것이다. 두 잠재변수간의 AVE 값이 잠재변수간의 상관계수 값의 제곱보다 크면 판별 타당성이 있다고 한다. 확인적 요인분석 실시결과를 이용하여 AVE 값과 관련 변수들의 상관계수를 산출하여 정리하면 Table 4 와 같다. 제시된 표에서 보듯이 AVE 값은 잠재변수별 상관계수의 제곱 값 보다 모두 크기 때문에 판별 타당성이 확보되었다.

\section{7. 연구 모형 적합도 및 가설 분석}

Table 5 : Hypothesis and Mediating effect Analysis

\begin{tabular}{|c|c|c|c|c|c|c|c|c|c|c|c|c|}
\hline \multirow{2}{*}{\multicolumn{6}{|c|}{ Path Hypothesis }} & \multirow{3}{*}{$\begin{array}{l}\text { C.V. } \\
.183\end{array}$} & \multirow{3}{*}{$\begin{array}{c}\text { C.R. } \\
3.999\end{array}$} & \multirow{3}{*}{$\begin{array}{c}\mathbf{P} \\
* * *\end{array}$} & \multirow{3}{*}{ Result } & \multicolumn{2}{|c|}{ Indirect Effects } & \multirow[t]{3}{*}{ No-te } \\
\hline & & & & & & & & & & C.V & $p$ & \\
\hline $\mathrm{H} 1-1$ & \multirow{2}{*}{ Ubiquity } & $->$ & \multicolumn{3}{|c|}{ Satisfaction } & & & & & & & \\
\hline $\mathrm{H} 1-2$ & & $->$ & \multicolumn{3}{|c|}{ Flow } & .144 & 3.108 & .002 * & & & & \\
\hline $\mathrm{H} 2-1$ & \multirow{2}{*}{$\begin{array}{c}\text { Information } \\
\text { Quality }\end{array}$} & $->$ & \multicolumn{3}{|c|}{ Satisfaction } & .694 & 11.809 & $* * *$ & & & & \\
\hline $\mathrm{H} 2-2$ & & $->$ & \multicolumn{3}{|c|}{ Flow } & .439 & 7.773 & $* * *$ & & & & \\
\hline $\mathrm{H} 3-1$ & \multirow{2}{*}{$\begin{array}{l}\text { Subjective } \\
\text { Norms }\end{array}$} & $->$ & \multicolumn{3}{|c|}{ Satisfaction } & .182 & 4.820 & $* * *$ & & & & \\
\hline H3-2 & & $\rightarrow$ & \multicolumn{3}{|c|}{ Flow } & .186 & 4.806 & $* * *$ & & & & \\
\hline $\mathrm{H} 4-1$ & \multirow{2}{*}{$\begin{array}{c}\text { eWOM } \\
\text { Information }\end{array}$} & $->$ & \multicolumn{3}{|c|}{ Satisfaction } & .223 & 4.235 & $* * *$ & & & & \\
\hline $\mathrm{H} 4-2$ & & $->$ & \multicolumn{3}{|c|}{ Flow } & -.008 & -.147 & .883 & Reject & & & \\
\hline $\mathrm{H} 5$ & Satisfaction & $->$ & \multirow{2}{*}{\multicolumn{3}{|c|}{ Purchase Intention }} & .486 & 7.748 & $* * *$ & & & & \\
\hline $\mathrm{H} 6$ & Flow & $->$ & & & & .184 & 3.197 & $.001^{* *}$ & & & & \\
\hline $\mathrm{H} 7-1$ & Ubiquity & & \multirow{4}{*}{$\begin{array}{c}\text { Satisfaction } \\
\text { Flow }\end{array}$} & \multirow{4}{*}{$->$} & \multirow{4}{*}{$\begin{array}{l}\text { Purchase } \\
\text { Intention }\end{array}$} & .059 & 1.225 & .220 & Reject & .105 & .045 & Full M. \\
\hline $\mathrm{H} 7-2$ & $\begin{array}{l}\text { Information } \\
\text { Quality }\end{array}$ & & & & & .323 & 4.175 & $* * *$ & & .327 & .004 & Partial M. \\
\hline $\mathrm{H} 7-3$ & $\begin{array}{l}\text { Subjective } \\
\text { Norms }\end{array}$ & & & & & .079 & 1.923 & .054 & Reject & .125 & .003 & Full M. \\
\hline $\mathrm{H} 7-4$ & $\begin{array}{c}\text { eWOM } \\
\text { Information }\end{array}$ & & & & & -.113 & -2.105 & .035 & & .028 & $.432^{*}$ & Reject \\
\hline
\end{tabular}

${ }^{*} \mathrm{p}<.05,{ }^{* *} \mathrm{p}<.01$

Notes : C.V. : Coefficient value, Full M. : Full Mediation, Partial M. : Partial Mediation

\subsection{2. 가설 검증}

경로분석을 위하여 AMOS 23 에서 구조방정식모델링 (SEM)을 사용하였다. 가설을 검증한 결과는 Table 5 와 같으며 구전정보 에서 플로우(low)으로 가는 경로 $\mathrm{H} 4-2$ 의 유의확률은 $\mathrm{p}=0.883$, 편재성에서 구매의도 간의 경로 $\mathrm{H7}-1$ 은 $\mathrm{p}=0220$, 주관적 규범에서 구매의도 간의 경로 H7-3 은 $\mathrm{p}=0.054$ 이므로 유의 확률 적합 기준인 $\mathrm{P}<0.05$ 를 초과하여 기각되었고 나머지 가설은 모두 수용 되었다.

\section{8. 매개효과 및 조절 효과 분석}

\subsection{1. 매개효과 분석}

\subsection{1. 연구 모형 적합도 분석}

모바일 단말기를 사용하는 모바일 쇼핑몰 이용자를 중심으로 구매의도에 미치는 요인분석을 실시하였다. 본 연구 모형은 각 잠재변수들에 대한 탐색적 요인분석, 타당성 분석 등을 거쳐 최종 남은 측정항목에 의한 잠재변수들로 구성된 모형에 대하여 적합도 분석을 실시하였다. AMOS 23 에서 구조방정식 모델링 분석으로 통해 절대적합지수, 증분적합지수를 활용하여 적합도를 검증하였다. 분석을 실시한 결과 $x^{2}=52230$ 로 나타났다. 그리고 절대적합지수 $\mathrm{p}=000$, $x^{2} / \mathrm{df}=1.872, \mathrm{GH}=911, \mathrm{AGH}=887, \mathrm{RMR}=068, \mathrm{RMSEA}=.046$, 증분적합지수 $\mathrm{NH}=.949, \mathrm{IH}=976, \mathrm{CH}=.976, \mathrm{TL}=.972$ 로 적합하게 나타났다. 따라서, 본 연구에서 제시한 연구 모형을 적합하다고 판단하여 연구를 진행하였다. 
구매의도에 미치는 간접효과는 $125, \mathrm{p}=.003$ 이므로 유의하고, 직접 효과는 $0.079, \mathrm{p}=054$ 로 유의하지 않기 때문에 주관적 규범과 구매의도 사이에서도 만족과 플로우의 완전 매개를 확인하였다. 그러나 정보품질이 만족과 플로우를 경유하여 구매 의도에 미치는 간접효과는 327, $\mathrm{p}=.004$ 로 유의수준 보다 작기 때문에 유효하고 직접효과는 $323, \mathrm{p}=^{\star \star \star}$ 로 유효하므로 정보품질과 구매의도 사이에서는 만족과 플로우는 부분 매개로 밝혀졌다. 그리고 구전정보가 만족과 플로우를 경유하여 구매 의도에 미치는 간접효과는 $.028, \mathrm{p}=432$ 로 유의하지 않기 때문에 구전정보와 구매의도 사이에는 간접효과가 없는 것으로 나타났다.

\subsection{2. 조절효과 분석}

조절효과 분석을 위하여 만족을 제약모델 $\mathrm{CM} 1$ 로 하고 플로우 를 제약모델 $\mathrm{CM} 2$ 로 하여 의인화 집단을 low, high 로 구분하였다. 이를 자유모형과 제약모형으로 만들어 다중집단 분석을 실시하였다. 먼저 제약모델의 적합도를 살펴보면 Table 6 에서 알 수 있듯이 $\mathrm{p}$ 값은 .000 으로 모두 유의확률 충족, $\mathrm{x}^{2} / \mathrm{df}$ 은 모두 3 이하이고 $\mathrm{CH}$ 는 0.9 이상, RMSEA 는 0.05 보다 모두 작아 모델은 적합하다고 할 수 있다.

Table 6 : Results of Model Fit Analysis

\begin{tabular}{|c|c|c|c|c|c|c|}
\hline & CMIN & DF & $\mathbf{P}$ & $\mathbf{x}^{2} / \mathbf{d f}$ & CFI & RMSEA \\
\hline FM & 875.217 & 566 & .000 & 1.546 & .965 & .037 \\
\hline CM1 & 884.453 & 567 & .000 & 1.560 & .964 & .037 \\
\hline CM2 & 875.371 & 567 & .000 & 1.544 & .965 & .037 \\
\hline
\end{tabular}

Notes : M : Free Model, CM1(Constrained Model 1) : Information quality and Satisfaction, CM2Constrained Model 2): Information quality and Flow

다중집단분석 결과를 확인하면 Table 7 에서 알 수 있듯이 정보품질에서 만족 경로구간에 설정한 low 의인화 group 경로 $\mathrm{al}$, high 의인화 group 경로 a2 가 동일하다고 제약한 제약모형과 자유모델 간을 분석하였다. 분석결과는 $\mathrm{DF}=1, \mathrm{p}=.002, \Delta \mathrm{x}^{2}=9236$ 이므로 $x^{2}$ 분포표에서 자유도(D.F.) $=1$ 일 때 유의확률 $p<0.05$ 에서 일반적인 적합기준 $\Delta x^{2}>3.841$ 에 모두 적합한 것으로 나타났다. 따라서 정보품질과 만족 간의 영향관계는 지각된 의인화에 따라 그 정도가 달라질 것이라는 H8-1 가설은 수용되었다. 정보품질에서 플로우 경로 구간에 설정한 low 의인화 group 경로 b1 과 high 의인화 group 경로 $\mathrm{b} 2$ 가 동일 $(\mathrm{b} 1=\mathrm{b} 2)$ 하다고 제약한 제약 모형과 자유 모델 간을 분석하였다.

분석결과(Table 7) D.F=1 에서 $p=695$ 로 유의확률 $p<0.05$ 를 초과, $\Delta x^{2}$ $=154$ 로 적합기준 $\Delta x^{2}>3.841$ 에 미달하였다. 따라서 정보품질과 플로우
영향관계는 지각된 의인화에 따라 그 정도가 달라질 것이라는 H8-2 가설은 기각되었다.

Table 7 : Moderating effect Analysis

\begin{tabular}{|c|c|c|c|}
\hline Model & DF & $\Delta \mathbf{x}^{\mathbf{2}}$ & $\mathbf{P}$ \\
\hline Constrained model 1 & 1 & 9.236 & .002 \\
\hline Constrained model 2 & 1 & .154 & .695 \\
\hline
\end{tabular}

\section{5. 결론 및 시사점}

\section{1. 연구결과 학문적 의의 및 시사점}

본 연구는 모바일 쇼핑몰에서 제공되는 이미지 검색 서비스의 특성과 사회적 영향 특성, 그리고 지각된 의인화에 대한 선행연구를 검토하여 구매의도에 영향을 미치는 구성 요인들을 규명하였다. 특히 이번 연구의 의의는 정보품질과 만족 사이에 지각된 의인화의 긍정적 조절 효과가 있다는 것이 규명되어 인공지능의 도입을 통한 유통과학화에 관한 연구에 필요한 학문적 기여가 될 수 있을 것이다. 그리고 연구결과를 요약하면 다음과 같다. 첫째, 이미지 검색 특성의 하위 속성인 편재성과 정보품질은 만족과 플로우에 정(+)의 영향을 미치는 것으로 나타났다. 둘째, 사회적 영향 특성의 하위 속성인 주관적 규범은 이용자 만족과 플로우에 정(+)의 영향을 미치는 것으로 나타났으나, 구전정보는 만족에 정(+)의 영향을 미칠 것이라는 가설은 수용되었지만, 플로우에 대해 영향을 미칠 것이라는 가설은 기각되었다. 셋째, 편재성, 정보품질, 주관적 규범은 각각 만족과 플로우를 경유하여 구매의도에 영향을 미치므로 매개효과가 있는 것으로 확인되었 다. 그러나 구전정보는 만족과 플로우를 경유하여 구매의도에 영향을 미치지 않는 것으로 나타났다. 넷째, 지각된 의인화가 정보품질과 만족과의 영향 관계에서는 조절효과가 나타났으나, 정보품질과 플로우와의 영향관계에 관한 조절효과에 대한 가설은 기각되었다. 다섯째, 만족과 플로우는 구매의도에 정(+)의 영향을 미치는 것으로 나타났다.

연구결과 시사점은 다음과 같다. 첫째 이미지 검색 서비스에 서 가장 중요한 요인은 검색결과에 해당하는 정보품질이며, 이 정보품질은 지각된 의인화가 높을 수록 소비자는 만족감을 느끼고, 나아가 구매의도에 더 큰 영향이 미침을 확인하였다. 따라서 구매의도를 높이려면 인공지능을 활용하는 이미지 검색 서비스를 개발하면서 의인화를 도모하는 새로운 마케팅 전략이 필요할 것이다. 둘째 플로우 경험은 만족과 함께 구매의도에 영향을 미치는 것으로 나타났으므로 이미지 검색 서비스에 새로운 유희적인 요소 등 모바일 쇼핑에 대한 몰입도 향상에 필요한 전략을 강구하면 좋을 것이다. 셋째 스마트폰 
이용자와 기업의 일대일 맞춤형 유통채널로 볼 수 있는 특성을 고려하여 이용자의 다양한 욕구 충족과 검색결과의 정확도 향상 전략이 매우 중요하다.

따라서 이번 연구결과를 토대로 스마트폰 등 모바일 단말기를 활용하는 모바일 쇼핑 이용자들의 구매의도 향상을 위하여 이미지 검색 서비스 도입과 의인화를 반영하여 보다 즐거운 몰입 경험 제공으로 만족을 향상시키는 유통 과학화 전략을 제안할 수 있다.

\section{2. 연구의 한계 및 향후 연구방향}

인공지능을 활용하는 이미지 검색 서비스가 모바일 쇼핑몰 에 있어 도입기이므로 선행연구가 다양하지 않아 향후 다양한 연구의 시도가 필요할 것이다. 첫째, 인공지능을 활용하는 이미지 검색 서비스와 텍스트 검색, 챗봇서비스(음성 검색) 등과 결합 활용에 관한 것도 추가 연구가 필요할 것이다. 둘째, 모바일 쇼핑에서 구매의도를 높이려면 스마트폰 등 모바일 단말기의 특성 등을 고려하여 의인화 하부 속성에 대한 구체적인 요인을 추출하여 추가 연구할 필요가 있을 것이다. 셋째, 스마트폰은 개인화의 특성상 일대일 맞춤형 유통채널 성격이므로 전수조사 를 하지 못한 표본의 한계상 본 연구결과의 일반화는 곤란할 수 있으므로 다양한 후속 연구가 이루어져야 할 것이다.

\section{Reference}

Aggarwal, P., \& Mcgill, A. L. (2007). Is that car smiling at me? Schema congruity as a basis for evaluating anthropomorphized products. Journal of Consumer Research, 34(4), 468-479.

Agrebi, S., \& Jallais, J. (2015). Explain the intention to use smartphones for mobile shopping. Journal of Retailing and Consumer Services, 22(C), 16-23.

Ahn, T., Ryu, S., \& Han, I. (2004). The impact of the online and offline features on the user acceptance of Internet shopping malls. Electronic commerce research and applications, 3(4), 405-420.

Ajzen, I. (1991). The theory of planned behavior. Organizational Behavior and Human Decision Processes, 50(2), 179-211.

Ángela, P. L., \& Ángel, V. R. (2017). Hedonic and utilitarian effects of the adoption and use of social commerce. Cooperative and Networking Strategies in Small Business, 1, 155-173.

Astrid, M., Kramer, N. C., Gratch, J., \& Kang, S. H. (2010). It doesn't matter what you are! Explaining social effects of agents and avatars. Journal Computers in Human Behavior, 26(6), 1641-1650.

Au, Y. A., \& Kauffman, R. J. (2008). The economics of mobile payments: Understanding stakeholder issues for an emerging financial technology application. Electronic Commerce Research and Applications, 7(2), 141-164.
Baker, D. A., \& Crompton, J. L. (2000). Quality, satisfaction and behavioral intentions. Annals of Tourism Research, 27(3), 785804.

Bao, Z., \& Huang, T. (2018). Exploring stickiness intention of B2C online shopping malls (A perspective from information quality). International Journal of Web Information Systems, 14(2), 177-192.

Bilgihan, A., Nusair, K., Okumus, F., \& Cobanoglu, C. (2015). Applying flow theory to booking experiences: An integrated model in an online service context. International Journal of Social Economics, 45(1), 57-81.

Carolina, L. N., Francisco, J. M. C., \& Harry, B. (2008). An assessment of advanced mobile services acceptance: contributions from TAM and diffusion theory models. Information \& Management, 45(6), 359-364.

Cha, S. S., \& Lee, S. H. (2020). The effect of convenience store dessert on consumers value and satisfaction. Journal of Asian Finance, Economics and Business, 7(3), 191-199.

Cha, S. S., \& Seo, B. K. (2019). The effect of brand trust of home meal replacement on repurchasing in online shopping. Journal of Business, Economics and Environmental Studies, 9(3), 2126.

Cha, S. S., \& Lyu, M. S. (2019). Influence of SNS characteristics on the brand Image of infant food products. International Journal of Industrial Distribution \& Business, 10(8), 7-15.

Chandler, J., \& Schwarz, N. (2010). Use does not wear ragged the fabric of friendship: Thinking of objects as alive makes people less willing to replace them. Journal of Consumer Psychology, 20(2), 138-45.

Chang, E. C., \& Tseng, Y. F. (2013). E-store image, perceived value and perceived risk. Journal of Business Research, 66(7), 864-870.

Chatterjee, S., Kar, A. K., \& Gupta, M. P. (2018). Success of IoT in smart cities of India: An empirical analysis. Government Information Quarterly, 35(3), 349-361.

Chen, L. Y. (2013). Antecedents of customer satisfaction and purchase intention with mobile shopping system use. International Journal of Services and Operations Management, 15(3), 259-274.

Cho, B. D., Potluri, R. M., \& Youn, M. K. (2020). A Study on the effect of product recommendation system on customer satisfaction: focused on the online shopping mall. Journal of Industrial Distribution \& Business, 11(2), 17-23.

Cho, S. H. (2019). The effect of mobile tourism App characteristics on perceived value, satisfaction and behavioral intention. International Journal of Industrial Distribution \& Business, 10(9), 45-52.

Cho, Y. C. (2020). Exploring determinants of performance indicator and customer satisfaction of accommodation sharing. Journal of Asian Finance, Economics and Business, 7(3), 201210.

Clarke, I. (2008). Emerging value propositions for M-commerce. Journal of Business Strategies, 18(2), 133-148.

Craig, S. D., \& Schroeder, N. L. (2017). Reconsidering the voice effect when learning from a virtual human. Computers \& Education, 114, 193-205.

Csikszentmihalyi, M. (1997). Creativity: Flow and the psychology of discovery and invention. New York, NY: Harper Perennial. 
Delone, W. H., \& McLean, E. R. (2003). The DeLone and McLean model of information systems success: a ten-year update. Journal of management information systems, 19(4), 930.

DeLone, W. H., \& McLean, E. R. (2016). Information Systems Success Measurement. Foundations and Trends in Information Systems, 2(1), 1-116.

Dwivedi, Y. K., Shareef, M. A., Simintiras, A. C., Lal, B., \& Weerakkody, V. (2016). A generalized adoption model for services: A cross-country comparison of mobile health (mhealth). Government Information Quarterly, 33(1), 174-187.

Engel, J., Blackwell, L., Roger, D., \& Miniard, P. W. (1995). Consumer behavior, Chicago. Journal of Retailing, 58(1), 3457.

Epley, N., Waytz, A., Akalis, S., \& Cacioppo, J. (2007). On seeing human: A three-factor theory of anthropomorphism. Psychological Review, 114(4), 864-886.

Epley, N., Waytz, A., Akalis, S., \& Cacioppo, J. (2008). When we need a human: Motivational determinants of anthropomorphism. Social Cognition, 26(2), 143-155.

Erkan, I., \& Evans, C. (2016). The influence of eWOM in social media on consumers' purchase intentions: An extended approach to information adoption. Computers in Human Behavior, 61, 47-55.

Estela, F. S., \& Sergio, R. (2016). The multichannel customer's service experience: Building satisfaction and trust. Service Business, 10(2), 423-445.

Fetscherin, M., \& Lattemann, C. (2008). User acceptance of virtual worlds. Journal of Electronic Commerce Research, 9(3), 231-242.

Fishbein, M. (1967). Readings in attitude theory and measurement (Ed.). New York, NY: John Wiley \& Sons.

Fornell, C., \& Larcker, D. F. (1981). Evaluating structural equation models with unobservable variables and measurement error. The Journal of Marketing Research, 18(1), 39-50.

Frolick, M. N., \& Chen, L. D. (2004). Assessing m-commerce opportunities. Information Systems Management, 21(2), 53-61.

Fu, X., Bin, Z., Xie, Q., Liuli, X., \& Yu, C. (2011). Impact of quantity and timeliness of eWOM information on consumer's online purchase intention under $\mathrm{C} 2 \mathrm{C}$ environment. Asian Journal of Business Research, 1(2), 37-52.

Ghani, J. A., \& Deshpande, S. P. (1994). Task characteristics and the experience of optimal flow in human-computer interaction. The Journal of psychology, 128(4), 381-391.

Hausman, A., \& Siekpe, J. (2009). The effect of web interface features on consumer online purchase intentions. Journal of Business Research, 62(1), 5-13.

Hoffman, D. L., \& Novak, T. P. (1996). Marketing in hypermedia computer-mediated environments: Concep-tual foundations. Journal of Marketing, 60(3), 50-68.

Horst, M., Kuttschreuter, M., \& Gutteling, J. M. (2007). Perceived usefulness, personal experiences, risk perception and trust as determinants of adoption of e-government services in the Netherlands. Computers in Human Behavior, 23(4), 18381852.

Hsiao, C. H., Chang, J. J., \& Tang, K. Y. (2016). Exploring the influential factors in continuance usage of mobile social Apps: Satisfaction, habit, and customer value persp- ectives. Telematics and Informatics, 33(2), 342-355.
Huang, L., Lu, X., \& Ba, S. (2016). An empirical study of crosschannel effects between web and mobile shopping channels. Information \& Management, 53(2), 265-278.

Iriobe, O. C., \& Elizabeth, A. O. (2019). Moderating effect of the use of eWOM on subjective norms, behavioural control and religious tourist revisit intention. International Journal of Religious Tourism and Pilgrimage, 7(3), 38-47.

Jalilvand, M. R., \& Samiei, N. (2012). The impact of electronic word of mouth on a tourism destination choice testing the theory of planned behavior(TPB). Internet Research, 22(5), 591-612.

Jamshidi, D., Keshavarz, Y., Kazemi, F., \& Mohammadian, M. (2018). Mobile banking behavior and flow experience: An integration of utilitarian features, hedonic features and trust. International Journal of Social Economics, 45(1), 57-81.

Jun, Z., \& Lee, H. Y. (2015). Factors influencing Chinese customers' selection of health care service countries: Focusing on word-of-mouth moderating effects. Journal of Distribution Science, 13(12), 41-52.

Jun, Z., \& Lee, H. Y. (2016). The word-of-mouth effects on the Chinese customers' choice intention of medical tourism destination. Journal of Distribution Science, 14(7), 21-31.

Kannan, P. K., Chang, A. M., \& Whinston, A. B. (2001). Electronic communities in e-business: Their role and issues. Information System Frontier, l(4), 415-426.

Kim, M. S., Kim, M. O., Hur, S. E., Seo, M. S., \& Seo, W. J. (2020). Promoting word-of-mouth communication: The moderating role of leisure sport social media. Journal of Distribution Science, 18(4), 61-72.

Kleijnen, M., Ruyter, K., \& Wetzels, M. (2007). An assessment of value creation in mobile service delivery and the moderating role of time consciousness. Journal of Retailing, 83(1), 33-46.

Koo, G. Y., Shoffner, S., \& Ryu, J. (2017). Use of animated pedagogical agent in sport management education: effect on students' situational interest. Sport Management Education Journal, 11(1), 34-44.

Kwak, J. G., Kim, N. E., \& Kim, M. S. (2019). The relationship among chatbot's characteristics, service value, and customer satisfaction. International Journal of Industrial Distribution \& Business, 10(3), 45-58.

Lee, W. S., \& Kim, B. Y. (2019). The effects of career orientations on entrepreneurial satisfaction and business sustainability. Journal of Asian Finance, Economics and Business, 6(4). 235-248.

Lim, H. Y., Jo, S. H., Kho, H. S., \& Han, K. S. (2019). A study on the effects of image search service on customers' purchase intention in mobile shopping mall. Journal of Digital Contents Society, 20(2), 363-375.

Limayem, M., \& Cheung, C. M. (2008). Understanding information systems continuance: The case of internet-based learning technologies. Information \& Management, 45(4), 227-232.

Lin, Y. H., Hsu, C. L., Chen, M. F., \& Fang, C. H. (2017). New gratifications for social word-of-mouth spread via mobile SNSs: Uses and gratifications approach with a perspective of media technology. Telematics and informatics, 34(4), 382-397.

Mariné, A. S., Forsythe, S., Kwon, W. S., \& Chattaraman, V. (2012). The role of product brand image and online store image on perceived risks and online purchase intentions for 
apparel. Journal of Retailing and Consumer Services, 19(3), 325-331.

McDougall, G. H. G., \& Levesque, T. (2000), Customer satisfaction with services: putting perceived value into the equation. Journal of Services Marketing, 14(5), 392-410.

Mohammad, I., \& Razli, C. R. (2011). The determinant factors influencing young consumers' acceptance of mobile marketing in Malaysia. African Journal of Business Management, 5(32), 12531-12542.

Moreno, R., Mayer, R. E., Spires, H. A., \& Lester, J. C. (2001). The case for social agency in computer-based teaching: Do students learn more deeply when they interact with animated pedagogical agents? Cognition and Instruction, 19(2), 177-213.

Negash, S., Ryan, T., \& Igbaria, M. (2003). Quality and effectiveness in web-based customer support systems. Information \& Management, 40(8), 757-768.

Nikou, S. A., \& Economides, A. A. (2017). Mobile-based assessment: Investigating the factors that influence behavioral intention to use. Computers \& Education, 109, 56-73.

Novak, T. P., \& Hoffman, D. L. (1996). Marketing in hyperme dia computer- mediated environments: Conceptual foun dations. Journal of Marketing, 60(3), 50-68.

Novak, T. P., Hoffman, D. L., \& Yung, Y. F. (2000). Measuring the customer experience in online environments: A structural modeling approach. Marketing Science, 19(1), 22-42.

Okazaki, S., \& Mendez, F. (2013). Perceived ubiquity in mobile services. Journal of Interactive Marketing, 27(2), 98-111

Osatuyi, B., \& Turel, O. (2019). Social motivation for the use of social technologies: An empirical examination of social commerce site users. Internet Research, 29(1), 24-45.

Park, S. Y., \& Park, E. J. (2013). The effects of flow on consumer satisfaction through e-impulse buying for fashion products. Fashion \& Textile Research Journal, 15(4), 533-542.

Pedersen, P. E. (2005). Adoption of mobile internet services: An exploratory study of mobile commerce early adopters. Journal of Organizational Computing, 15(2), 203-222.

Petter, S., \& McLean, E. R. (2009). A meta-analytic assessment of the DeLone and McLean IS success model: An examination of IS success at the individual level. Information \& Management, 46(3), 159-166.

Pitt, L. F., Watson, R. T., \& Kavan, C. B. (1995). Service quality: A measure of information systems effectiveness. MIS Quarterly 19(2), 173-187.

Sarkara, S., Chauhanb, S., \& Khare, A. (2020). A meta-analysis of antecedents and consequence influence of expectation confirmation, network externalities, and flow on use of $s$ of trust in mobile commerce. International Journal of Information Management, 50, 286-301.

Sarkar, S., \& Khare, A. (2019). Influence of expectation confirmation, network externalities, and flow on use of mobile shopping Apps. International Journal of Human-Computer Interaction, 35(16), 1449-1460.

Seddon, P. B. (1997). A respecification and extension of the DeLone and McLean model of IS success. Information systems research, 8(3), 240-253.

Sharma, S. K., \& Sharma, M. (2019). Examining the role of trust and quality dimensions in the actual usage of mobile banking services: An empirical investigation. International Journal of Information Management, 44, 65-75.
Shaw, N., \& Sergueeva, K. (2019). The non-monetary benefits of mobile commerce: Extending UTAUT2 with perceived value. International Journal of Information Management, 45, 44-45.

Siau, K., Lim, E. P., \& Shen, Z. (2001). Mobile commerce: Promises, challenges, and research agenda. Journal of Database Management, 12(3), 4-13.

Sonia, S. M., Jana, P., \& Blanca, L. C. (2016). What makes services customers say "Buy it with a mobile phone?". Journal of Services Marketing, 30(6), 601-614.

Swan, M. (1985). A critical look at the communicative approach (1). English Language Teaching Journal, 39(1), 2-12.

Tojib, D., \& Tsarenko, Y. (2012). Post-adoption modeling of advanced mobile service use. Journal of Business Research, 65(7), 922-928.

Trevino, L. K., \& Webster, J. (1992). Flow in computer-mediated communication electronic mail and voice mail evaluation and impacts. Communication research, 19(5), 539-573.

Venkatesh, V., \& Davis, F. D. (1996). A model of the antecedents of perceived ease of use: Development and test. Decision Sciences, 27(3), 451-481.

Venkatesh, V., \& Davis, F. D. (2000). A theoretic al extension of the technology acceptance model: Four longitudinal field studies. Management Science, 46(2), 186-204.

Venkatesh, V., Morris, M. G., \& Davis. F. D. (2003). User acceptance of information technology: Toward a unified view. Management Information Systems Quarterly, 27(3), 425478.

Wan, E. W., Chen, R. P., \& Jin, L. (2017). Judging a book by its cover? The effect of anthropomorphism on product attribute processing and consumer preference. Journal of Consumer Research, 43(6), 1008-1030.

Wang, K., \& Huang, S. T. (2014). How flow experience affects intention to use musicstreaming service: Model development. Proceeding of the 12th International Conference on Advances in Mobile Computing and Multimedia, 451-457.

Wang, N., Shen, X. L., \& Sun, Y. (2013). Transition of electronic word-of-mouth services from web to mobile context: A trust transfer perspective. Decision Support Systems, 54(3), 13941403.

Waytz, A., Morewedge, C. K., Epley, N., Monteleone, G., Gao, J. H., \& Cacioppo, J. T. (2010). Making sense by making sentient: Effectance motivation increases anthropomor phism. Journal of Personality and Social Psychology, 99(3), 410-435.

Webster, J., Trevino, L. K., \& Ryan, L. (1993). The dimension ality and correlates of flow in human-computer interac tions. Computers in Humans Behavior, 9(4), 411-426.

Wells, J. D., Parboteeah, V., \& Valacich, J. S. (2011). Online impulse buying: Understanding the interplay between consumer impulsiveness and website quality. Journal of the Association for Information Systems, 12(1), 32-56.

Wixom, B. H., \& Todd, P. A. (2005). A theoretical integration of user satisfaction and technology acceptance. Information Systems Research, 16(1), 85-102.

Wolf, L., Bick, M., \& Kummer, T. F. (2017). The influence of situation dependent factors on mobile shopping usage. Proceedings of the 50th Hawaii International Conference on System Sciences, 4169-4178. Honolulu, HI: HICSS. Retrieved from http://hdl.handle.net/10125/41664.

Wu, J. J., \& Chang, Y. S. (2005). Towards understanding members' interactivity, trust, and flow in online travel 
community. Industrial Management \& Data Systems, 105(7), 937-954.

Xiang, L., Zheng, X., Lee, M. K. O., \& Zhao, D. (2016). Exploring consumers' impulse buying behavior on social commerce platform: The role of parasocial interaction. International Journal of Information Management, 36(3), 333347.

Yadav, R., Sharma, S.K., \& Tarhini, A. (2015). A multi analytical approach to understand and predict the mobile commerce adoption. Journal of Enterprise Information and Management, $29(2), 222-237$.
Yoo, C. K., \& Kim, G. P. (2019). An empirical analysis on the compromised delivery model of traditional market using delivery application. International Journal of Industrial Distribution \& Business, 10(10), 45-51.

Zhou, T., \& Lu, Y. (2011). The effect of interactivity on the flow experience of mobile commerce user. International journal of mobile communication, 9(3), 225-242.

Zhu, F. X., Wymer, W., \& Chen, I. (2002). IT-based services and service quality in consumer banking. International Journal of Service Industry Management, 13(1), 69-90. 